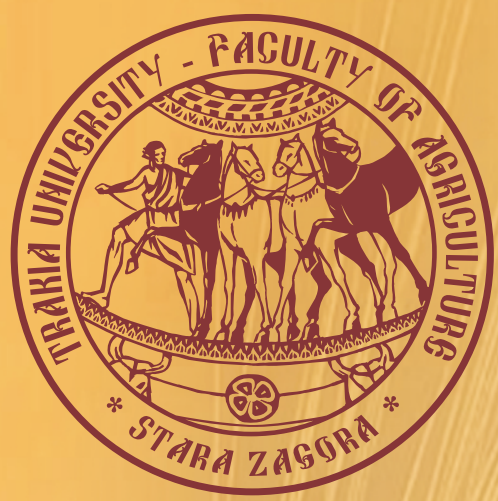

ISSN $1313-8820$ (print)

ISSN 1314 - 412X (online)

Volume 9 , Number 3

September 2017

\title{
AGRICULTURAL
}

\section{SCIENCE AND TECHNOLOGY}

\section{7}

An International Journal Published by Faculty of Agriculture, Trakia University, Stara Zagora, Bulgaria 


\section{Editor-in-Chief}

Georgi Petkov

Faculty of Agriculture

Trakia University, Stara Zagora

Bulgaria

E-mail: gpetkov@af.uni.sz.bg

\section{Co-Editor-in-Chief}

Dimitar Panayotov

Faculty of Agriculture

Trakia University, Stara Zagora

Bulgaria

\section{Editors and Sections}

\section{Genetics and Breeding}

Tsanko Yablanski (Bulgaria)

Atanas Atanasov (Bulgaria)

Svetlana Georgieva (Bulgaria)

Nikolay Tsenov (Bulgaria)

Max Rothschild (USA)

Ihsan Soysal (Turkey)

Horia Grosu (Romania)

Stoicho Metodiev (Bulgaria)

Bojin Bojinov (Bulgaria)

\section{Nutrition and Physiology}

Nikolai Todorov (Bulgaria)

Peter Surai (UK)

Ivan Varlyakov (Bulgaria)

George Zervas (Greece)

Vasil Pirgozliev (UK)

\section{Production Systems}

Radoslav Slavov (Bulgaria)

Dimitar Pavlov (Bulgaria)

Bogdan Szostak (Poland)

Banko Banev (Bulgaria)

Georgy Zhelyazkov (Bulgaria)

\section{Agriculture and Environment}

Martin Banov (Bulgaria)

Peter Cornish (Australia)

Vladislav Popov (Bulgaria)

Tarek Moussa (Egypt)

\section{Product Quality and Safety}

Stefan Denev (Bulgaria)

Vasil Atanasov (Bulgaria)

Roumiana Tsenkova (Japan)

\section{English Editor}

Yanka Ivanova (Bulgaria)
Scope and policy of the journal

Agricultural Science and Technology /AST/

- an International Scientific Journal of Agricultural and Technology Sciences is published in English in one volume of 4 issues per year, as a printed journal and in electronic form. The policy of the journal is to publish original papers, reviews and short communications covering the aspects of agriculture related with life sciences and modern technologies. It will offer opportunities to address the global needs relating to food and environment, health, exploit the technology to provide innovative products and sustainable development. Papers will be considered in aspects of both fundamental and applied science in the areas of Genetics and Breeding, Nutrition and Physiology, Production Systems, Agriculture and Environment and Product Quality and Safety. Other categories closely related to the above topics could be considered by the editors. The detailed information of the journal is available at the website. Proceedings of scientific meetings and conference reports will be considered for special issues.

\section{Submission of Manuscripts}

There are no submission / handling / publication charges.

All manuscripts written in English should be submitted as MS-Word file attachments via e-mail to editoffice@agriscitech.eu. Manuscripts must be prepared strictly in accordance with the detailed instructions for authors at the website

www.agriscitech.eu and the instructions on the last page of the journal. For each manuscript the signatures of all authors are needed confirming their consent to publish it and to nominate on author for correspondence.

They have to be presented by a submission letter signed by all authors. The form of the submission letter is available upon from request from the Technical Assistance or could be downloaded from the website of the journal. Manuscripts submitted to this journal are considered if they have submitted only to it, they have not been published already, nor are they under consideration for publication in press elsewhere. All manuscripts are subject to editorial review and the editors reserve the right to improve style and return the paper for rewriting to the authors, if necessary. The editorial board reserves rights to reject manuscripts based on priorities and space availability in the journal.

The journal is committed to respect high standards of ethics in the editing and reviewing process and malpractice statement. Commitments of authors related to authorship are also very important for a high standard of ethics and publishing. We follow closely the Committee on Publication Ethics (COPE), http://publicationethics.org/resources/guid elines

The articles appearing in this journal are indexed and abstracted in: DOI, EBSCO Publishing Inc., AGRIS (FAO) and DOAJ.

The journal is accepted to be indexed with the support of a project № BG051P00013.3.05-0001 "Science and business" financed by Operational Programme "Human Resources Development" of EU. The title has been suggested to be included in SCOPUS (Elsevier) and Electronic Journals Submission Form (Thomson Reuters).

The journal is freely available without charge to the user or his/her institution. Users can read, download, copy, distribute, print, search, or link to the full texts of the articles, or use them for any other lawful purpose, without asking prior permission from the publisher or the author.

This issue is printed with the financial support by Contract No DNP 0521/20.12.2016, financed from Fund 'Scientific Research' grant Bulgarian scientific Periodicals.

\section{Address of Editorial office:}

Agricultural Science and Technology Faculty of Agriculture, Trakia University

Student's campus, 6000 Stara Zagora

Bulgaria

Telephone: +35942699330 $+35942699446$

www.agriscitech.eu

Technical Assistance:

Nely Tsvetanova

Telephone: +359 42699446

E-mail:editoffice@agriscitech.eu 


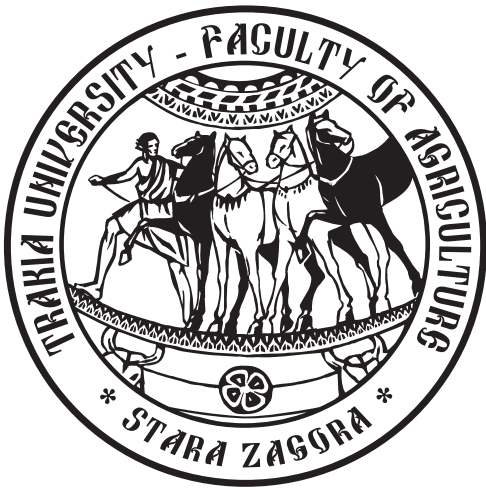

AGRICULTURAL

SCIENCE AND TECHNOLOGY

\section{7}

An International Journal Published by Faculty of Agriculture,

Trakia University, Stara Zagora, Bulgaria 


\title{
Mathematical approaches for assessment and classification of the European Union member states based on the average yield of vegetables for the period 1961-2014
}

\author{
N. Keranova* \\ Faculty of Economics, Agricultural University-Plovdiv, 4000 Plovdiv, Bulgaria
}

(Manuscript received 30 May 2017; accepted for publication 27 July 2017)

\begin{abstract}
The objective of this work is to analyze the statistical data on the average yield of vegetables in the European Union member states for the period 1961 - 2014. The EU countries are classified and grouped through hierarchical cluster analysis based on the average yield of vegetables. A mathematical model for evaluation of the received data is composed through a single-factor analysis of variance (ANOVA). The results show that the countries with the highest yields are Belgium (33.81 t/ha), Austria (29.39 t/ha) and the Netherlands (27.76 t/ha), while the lowest yields are in Bulgaria (4.05 t/ha) and Luxembourg $(0.19 \mathrm{t} / \mathrm{ha})$. Dependencies have been identified between the change in the average yields in Bulgaria, Greece and Romania and time. It was found that they were modeled by polynomial regression models of second degree.
\end{abstract}

Keywords: hierarchical cluster analysis, mathematical model, vegetables

\section{Introduction}

Vegetable farming has been a traditional brunch of plantgrowing in our country. The reasons for this are the favorable environmental conditions as well as the experience of our population. After exploring the foreign experience, it has been found that such large-scale studies in the field of average yields of vegetables haven't been carried out (on the one hand - the long period, on the other - all EU member states). There are many studies in the field of agrarian sciences based on mathematicalstatistical methods, but they are oriented to more specific objects. Pagluanan and Anical (1995) apply statistical methods to study the yields of several types of vegetables over a five-month period. The study was conducted to determine the effects of organic fertilizers on the growth of different vegetables and to find out which among the different vegetables will give the best yield when applied with organic fertilizers. The study was conducted from October 2009 to February 2010 at ASIST (Abra State Inst. of Sciences and Technology) Main Campus, Lagangilang, Abra (Philippines). The experiment was laid out following a Randomized Complete Block Design. The five different vegetables were tomato, mungbean, cowpea, pepper and eggplant set in each treatment with three blocks.

In another publication (Auwalu et al., 2007) correlation and regression analyses were applied to study data on the growth and yields of vegetable sesame after treatment with nitrogen and phosphorus. It was found that the yield in this case is strongly dependent on the height of the plant, the number of leaves and their index. In 2009, the quantity of arable lands and the average yields of vegetables in the EU countries and in Serbia were analyzed for the period 2003-2007 (Puskaric et al., 2009). The research is based on available data and uses the desk research method. There is no grouping of the EU countries according to statistically proven similarity in the explored indicator or a comparative analysis between them (based on mathematical and statistical methods and relevant criteria).
The main objectives of the present work could be summarized in the following directions:

- to group the EU countries according to a degree of similarity in the average yields of vegetables from 1961 to 2014;

- to make a comparative assessment based on the given criterion;

- to explore in greater depth and detail the alteration in the average yields in Bulgaria, Romania and Greece through a combination of the following methods: building of graphs, establishing the degree of relation between the output and the year, and presenting the resulting relations in analytical form.

\section{Material and methods}

The evaluation and analysis in this work are based on data on the average yields of vegetables in all member states of the European Union for the period 1961-2014. The research is based on data extracted from the relational database FAOSTAT. Microsoft Access provides the possibility to export tables from the corresponding database directly into the medium of MS Excel or SPSS by which the statistical processing is performed (Dimova, 2013).

One of the methods of grouping of the EU countries by indicator "average vegetables yield" for the period 1961-2014, used in the present work, is a hierarchical cluster analysis (Ho, 2013). The method of intergroup connection is used and the criterion of similarity according to which it is realized is the Euclidean distance. It is known that in the method of intergroup connection the distance between two clusters $A$ and $B$ is defined as the average value of $n A . n B$ of a number of distances between $n A$ points from $A$ and $n B$ points from $B$ :

$$
D(A, B)=\frac{1}{n_{A} n_{B}} \sum_{i=1}^{n_{A}} \sum_{j=1}^{n_{B}} d\left(x_{i}, x_{j}\right)
$$

*e-mail: nelikeranova@abv.bg 
and $d\left(x_{i}, x_{j}\right)=\sqrt{\sum_{m=1}^{p}\left(x_{i m}-x_{j m}\right)^{2}}, i, j=\overline{1, n}$

is the ordinary Euclidean distance between two vectors $x_{\mathrm{i}}\left(x_{\mathrm{i}}, x_{\mathrm{i}}, \ldots, x_{\mathrm{ip}}\right)$ and $x_{\mathrm{i}}\left(x_{\mathrm{i} 1}, x_{\mathrm{i} 2}, \ldots, x_{\mathrm{ip}}\right)$. A dendrogram is built presenting graphically the formed clusters. It was found that the organization of the EU countries in clusters by this method corresponds to the assessment obtained by a single-factor analysis of variance (Genchev et al., 1975; Barov, 1982). Mathematical models were built, using regression analysis, giving the connection in the change in the average yields of vegetables over time. The data processing was performed through the statistical program IBM Statistics SPSS 24 (Abramowitz etal., 2016; Cronk, 2016; Ganeva, 2016).

\section{Results and discussion}

The data on the average yield of vegetables in the Member States of the European Union from 1961 to 2014 are processes and analyzed by several mathematical methods. We use hierarchical cluster analysis to organize the countries in groups according to the quantity of the produced output.

Bulgaria, Greece and Romania are countries with similar geographical and climatic features. Therefore, this work studies the change in the average yields of vegetables from 1961 to 2014 in these countries. Mathematical models describing the statistical data were built. The coefficients of correlation and determination of these data were defined. It was found that the dependence of the changes in the average yields on time for these countries is modeled by polynomial regression models of second degree.

As a result of its implementation, the EU Member States were grouped into 8 clusters according to the degree of similarity of the average yields of vegetables from 1961 to 2014 , which are depicted on the dendrogram in Figure 1.

Since in the cluster analysis no tests for statistical significance are made, we apply a single-factor analysis of variance (ANOVA). The results show that the countries with the highest yields are Belgium (33.81t/ha), Austria (29.39 t/ha) and the Netherlands (27.76 t/ha), while the lowest yields are in Bulgaria (4.05 t/ha) and Luxembourg $(0.19 \mathrm{t} / \mathrm{ha})$.

The assessment of the EU countries in the average yield of vegetables according to their belonging to the respective cluster is presented in Table 1.

\section{Dendrogram using Average Linkage (Between Groups) \\ Rescaled Distance Cluster Combine}

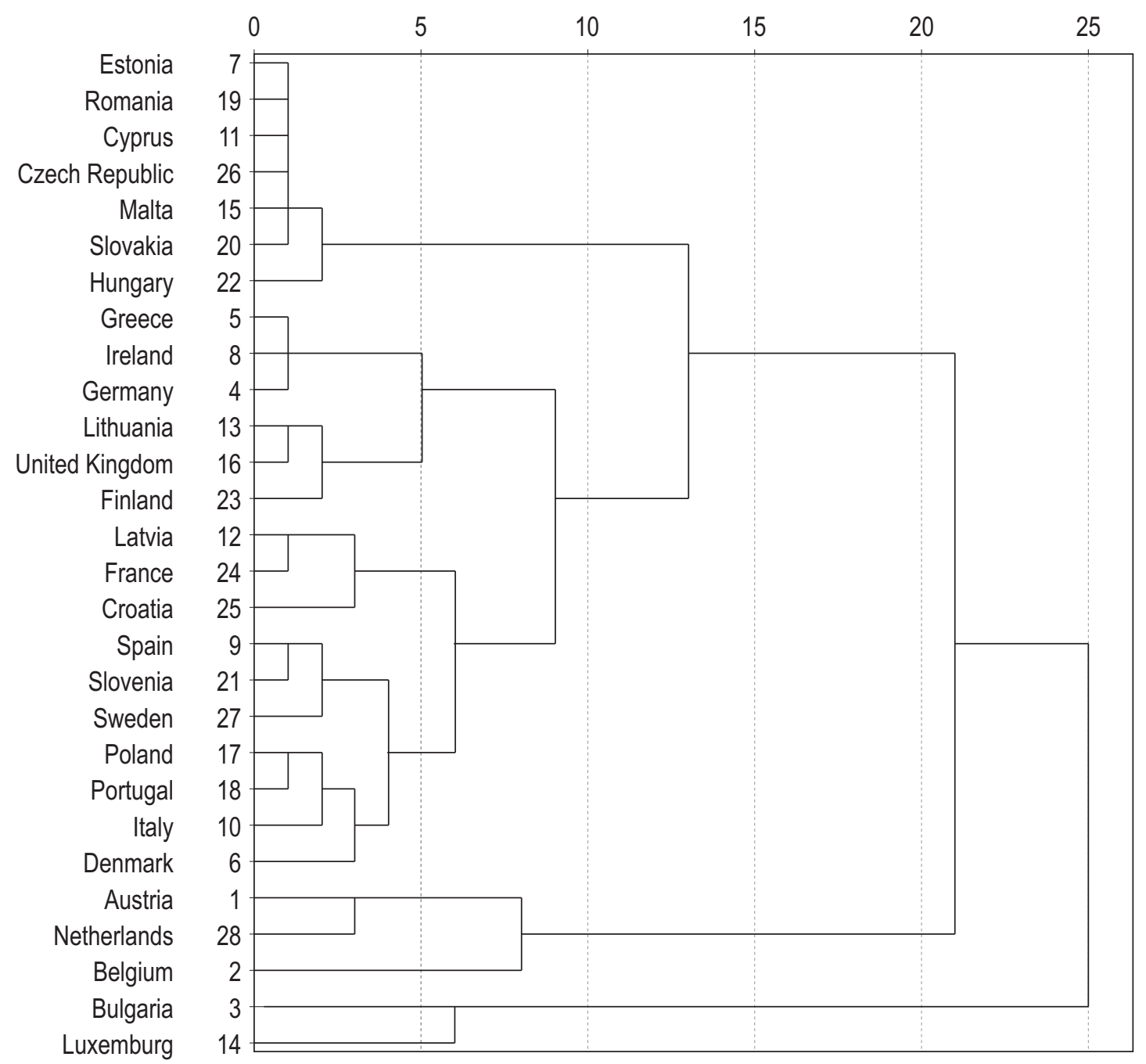

Figure 1. Hierarchical cluster analysis according to the average yield (t/ha) of vegetables for the period 1961-2014 
Clusters 5 and 6 include the countries with the highest average yields of vegetables - Austria, the Netherlands and Belgium.

Cluster 2 includes the countries which follow, based on their volume of production, with average yields, statistically different from the average yields of the countries from clusters 5 and 6 . The highest yields are in the United Kingdom, Lithuania and Finland. The first two of them, however, have unsustainable production of vegetables, which is evident from the statistical indicator of variation, which is 11.0 and 11.613 , respectively. Bulgaria has the lowest average yield of vegetables ( $4.05 \mathrm{t} / \mathrm{ha}$ ) and can be viewed as a standalone cluster or can form a generalized cluster together with Luxembourg. These two countries have sustainable production of vegetables. Their indicator of variation is one of the lowest.

Clusters 3 and 4 have higher level of similarity in the average yield and can be considered as a generalized cluster.

According to the results of Levene's test for homogeneity, we can say that the data on the yield of vegetables in the respective countries have equal dispersion, and can be compared according to the selected criteria.

Table 1. Evaluation of the average yields of the EU countries by the method of Duncan, $a, b, c, \ldots$ - degree of proof at significance level $a=0.05$

\begin{tabular}{|c|c|c|c|}
\hline $\begin{array}{l}\text { Cluster } \\
\text { No. }\end{array}$ & Country & $\begin{array}{c}\text { Average yield } \\
\text { (t/ha) }\end{array}$ & $\begin{array}{l}\text { Standard } \\
\text { deviation }\end{array}$ \\
\hline \multirow[t]{7}{*}{1} & Estonia & $11.44^{\mathrm{lm}}$ & 4.848 \\
\hline & Cyprus & $11.35^{\mathrm{mm}}$ & 3.571 \\
\hline & Romania & $11.44^{\mathrm{lm}}$ & 3.158 \\
\hline & Slovakia & $10.79^{\mathrm{lm}}$ & 1.726 \\
\hline & Malta & $11.69^{\mathrm{m}}$ & 1.798 \\
\hline & Czech Republic & $11.2^{\mathrm{lm}}$ & 3.516 \\
\hline & Hungary & $10.03^{\mathrm{m}}$ & 3.786 \\
\hline \multirow[t]{6}{*}{2} & Germany & $21.79^{\text {efg }}$ & 13.008 \\
\hline & Greece & $21.52^{\mathrm{fg}}$ & 5.556 \\
\hline & Ireland & $21.5^{\mathrm{fg}}$ & 2.18 \\
\hline & Lithuania & $24.7^{\text {de }}$ & 11.613 \\
\hline & United Kingdom & $25.26^{c d}$ & 11 \\
\hline & Finland & 23.89 def & 5.43 \\
\hline \multirow[t]{3}{*}{3} & Latvia & $15.44^{\mathrm{jk}}$ & 7.32 \\
\hline & France & $15.53^{\mathrm{jk}}$ & 5.09 \\
\hline & Croatia & $14^{\mathrm{kl}}$ & 4.012 \\
\hline \multirow[t]{7}{*}{4} & Spain & $16.96^{\mathrm{jk} k}$ & 2.851 \\
\hline & Slovenia & $16.96^{\mathrm{jk}}$ & 3.985 \\
\hline & Sweden & $17.63^{\text {hij }}$ & 3.029 \\
\hline & Poland & $18.6^{\text {ghij }}$ & 6.602 \\
\hline & Portugal & $18.6^{\text {ghij }}$ & 1.988 \\
\hline & Denmark & $20.19^{g h}$ & 3.14 \\
\hline & Italy & $19.3^{\text {ghi }}$ & 3.441 \\
\hline \multirow[t]{2}{*}{5} & Austria & $29.39^{b}$ & 6.644 \\
\hline & The Netherlands & $27.76^{\mathrm{bc}}$ & 5.98 \\
\hline 6 & Belgium & $33.81^{\mathrm{a}}$ & 1.354 \\
\hline 7 & Bulgaria & $4.05^{n}$ & 2.109 \\
\hline 8 & Luxembourg & $0.19^{\circ}$ & 0.06 \\
\hline
\end{tabular}

The overall statistical evaluation shows level of significance less than the error $a=0.05$, which is enough to consider that the average yields of vegetables in the 28 member states of the EU have statistical differences and that the overall model is statistically significant.

The standard deviation characterizes the average value of scattering around the average yield of the respective production. The high standard deviations of Germany, Lithuania and the United Kingdom are proof of the temporal unsustainability of the quantity of the produced vegetables. The average yields in Luxembourg, Belgium and Slovakia are comparatively more sustainable.

Figure 2 shows graphically the changes in the average yields of vegetables in Greece, Bulgaria and Romania with the purpose of determining the degree of influence of the geographical and climatic characteristics of the region on the studied indicator. It turns out that for the entire period 1961-2014 the production of Greece exceeds that in Romania and Bulgaria. Unfortunately, it appears that our country has the lowest production levels for the entire period, regardless of the ups and downs in the average yields of the other two countries over time.

Two periods can be observed in Greece: the first one covers the period from 1961 to 1975, when there is a clear increase in the average yields, while in the second period - till 2014, there are smooth ups and downs, but as a whole there is a tendency of growth in the production of vegetables.

In Bulgaria, from 1974 to 1995, we have relatively constant yields. From 1995 to 1997 there was a strong growth in production and from 1998 to 1999 - a decline. From 2000 to 2010 the production is relatively stable over time. In 2010 there was a sharp rise in yields, which was unfortunately followed by a sharp decline a year later.

Three periods stand out in the average yields of Romania. The first covers the time from 1961 to 1988 when there are smooth peaks and drops, but as a whole the output is stable. The period from 1989 to 2010 is characterized by strong peaks and decreases in the quantity of the produced vegetables (this fact is also evidenced by the value of the standard deviation from Table 1 , showing instability of the yields over time). After 2010, there were again smooth ups and downs.

The statistical data in the present work are modeled by regression equations, giving the dependence of the average yields

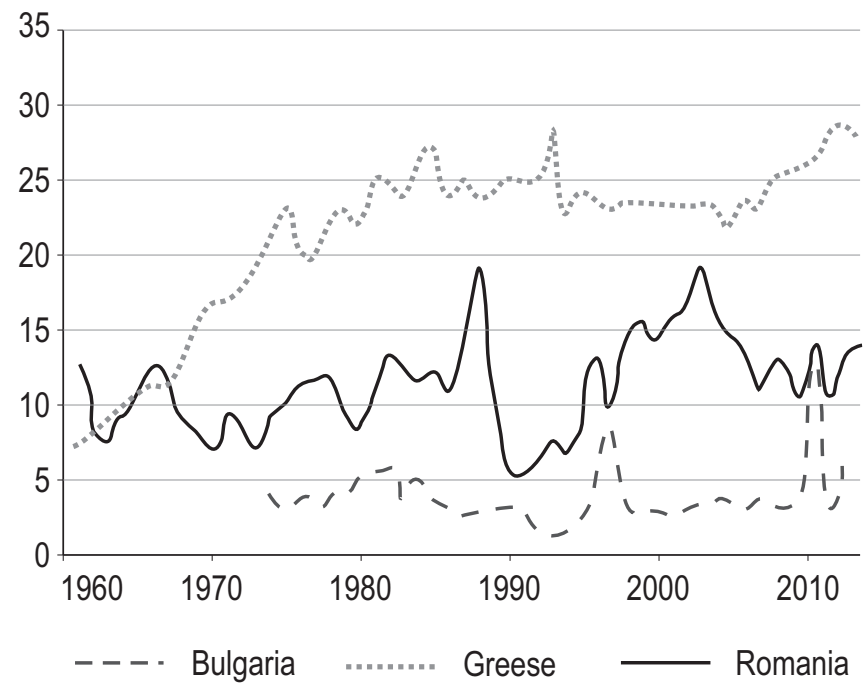

Figure 2. Graphical presentation of the changes in the average yields of vegetables in Greece, Bulgaria and Romania 
Table 2. Results from regression analysis of the average yield of vegetables in Bulgaria, Romania and Greece

\begin{tabular}{lc}
\hline \hline Country & \multicolumn{1}{c}{ Regression equation } \\
\hline Bulgaria & $y=0.0063 x^{2}-25.272 x+25174$ \\
Romania & $y=0.0009 x^{2}-3.4483 x+3350.2$ \\
Greece & $y=-0.0118 x^{2}+47.145 x-47103$ \\
\hline \hline
\end{tabular}

of vegetables in Bulgaria, Greece and Romania on time. The results of this analysis are shown in Table 2. It has been established that for all three countries, the vegetable yields are modeled by polynomial regression models of second degree.

From the obtained mathematical models and the evaluations of the statistical data, we can conclude that the average yields of vegetables are not dependent on the EU and the support policy that it leads towards farmers. Proof of this are the differences in the yields of Bulgaria and Romania, which joined the EU at the same time, as well as the close yields between Bulgaria and Luxembourg (joined in 1958). On the grounds of these conclusions we can consider that the reasons for the low yield of vegetables in Bulgaria are due to the national policy in this sector rather than to global European policies. The factors that led to this state of vegetable production could be the financing of manufacturers, the provision of markets for the finished products, the transport infrastructure (due to the perishability of the vegetable production), the return of a large part of the agricultural land to the owners, etc.

\section{Conclusion}

The mathematical models that are built not only present in analytical form the relation between the average yields of vegetables and the respective year of research. They allow each researcher to predict the alteration of this indicator in the near future. The graphical presentation, in turn, visualizes the flow of the average yields over time. This is another mathematical approach for comparative analysis of the yields between the countries. The countries with the highest average yields of vegetables are Austria, the Netherlands and Belgium, while the lowest yields are in Bulgaria and Luxembourg. The regression analysis has established that for Bulgaria, Greece and Romania data for the vegetable yields are modeled by polynomial regression models of second degree.

\section{References}

Auwalu B and Babatunde F, 2007. Analyses of Growth, Yield and Fertilization of Vegetable Sesame. Journal of Plant Sciences, 2, 108-112.

Barov V, 1982. Analysis and schemes of the Polish experience. NAPS, Sofia, Bulgaria $(\mathrm{Bg})$.

Cronk B, 2016. How to Use SPSS: A Step-By-Step Guide to Analysis and Interpretation, Routledge.

Dimova D, 2013. Application on mathematical-statistical methods for assessment of datasets on crop production in Balkan countries. Proceedings of international conference "Automatics and Informatics'2013", Sofia, Bulgaria, I-9, l-12 (Bg).

Ganeva Z, 2016. To rediscover the statistics with SPSS. Elestra, Sofia, Bulgaria $(\mathrm{Bg})$.

Abramowitz S and Weinberg S, 2016. Statistics Using IBM SPSS, An Integrative Approach, Cambridge University Press.

Genchev G, Marinkov E, Jovchev V and Ognjanova A, 1975. Biometric methods in plant genetics and breeding. Zemizdat, Sofia, Bulgaria $(\mathrm{Bg})$.

Ho R, 2013. Handbook of Univariate and Multivariate Data Analysis with IBM SPSS, Second Edition, Robert Ho, CRC Press.

Pagluanan E and Anical R, 1995. Growth and yield performance of different vegetables applied with organic fertilizers, Journal of the International Society for Southeast Asian Agricultural Sciences, http://aims.fao.org/serials/c_3dd81e20.

Puskaric A, Jelocnik M and Ivanovic L, 2009, Analysis of Vegetable Production in the European Union with Retrospection on the Conditions in Republic of Serbia. Buletinul Universitatii Petrol Gaze din Ploiesti, LXI, 36-43. 
Reviews

Problems and achievements of cotton (Gossypium Hirsutum L.) weeds control

T. Barakova, G. Delchev

Achievements and problems in the weed control in grain sorghum (Sorghum Bicolor Moench.)

G. Delchev, M. Georgiev

\section{Genetics and Breeding}

Parthenogenetic responsiveness of sunflower hybrid combinations with expressed tolerance to herbicides

M. Drumeva, P. Yankov

In vitro propagation of oil-bearing rose (Rosa damascena Mill.)

V. Badzhelova

\section{Nutrition and Physiology}

Variation in the chemical composition and physical characteristics of grain from winter barley varieties

B. Dyulgerova, N. Dyulgerov, D. Dimova

Haematological and serum biochemical indices of broiler chickens fed raw sickle pod (Senna obtusifolia) seed meal

C. Augustine, I.D. Kwari, J.U. Igwebuike, S.B. Adamu

Prey size selectivity of pikeperch (Sander Lucioperca L.) fed with topmouth gudgeon (Pseudorasbora Parva Temminck \& Schlegel)

M. Gevezova-Kazakova, M. Yankova, T. Hubenova, A. Zaikov, G. Rusenov

Influence of organic nitrogen amendment, containing amino acids on the cellulase and xylanase, produced by Trichoderma spp. isolates

D. Draganova, I. Valcheva, Y. Kuzmanova, M. Naydenov

\section{Production Systems}

Justification of a method for determining the moment for switching on the level one signaling of filled grain harvester hoppers

G. Tihanov, B. Kolev, K. Trendafilov, N. Delchev, Y. Stoyanov

Mathematical approaches for assessment and classification of the European Union member states based on the average yield of vegetables for the period 1961-2014

N. Keranova 
Present status of Zymoseptoria tritici (Mycospharella graminicola /Fuckel/ Schroter) of the wheat cultures in the Republic of Macedonia

I. Karov, E. Arsov

\section{Agriculture and Environment}

Influence of basic agrotechnical activities on the productivity and yield of Triticum monococcum $\mathrm{L}$.

S. Stamatov, K. Uzundzhalieva, E. Valchinova, G. Desheva, P. Chavdarov, B. Kyosev, T. Cholakov, R.

Ruseva, N. Velcheva

Avifauna abundance and diversity in Jos wildlife park, Nigeria

B.T. Kwaga, D. lliya, A. Ali, D. Khobe

Ecological analysis of the flora in the 'Chinarite' protected area - Rodopi municipality, Bulgaria

L. Dospatliev, M. Lacheva

Product Quality and Safety

Food emulsions with amidated pectin from celery (Apium graveolens var. rapaceum D. C.) tubers Iv. Petrova, N. Petkova, M. Ognyanov, Ap. Simitchiev, M. Todorova, P. Denev

M. Tonchev, T. Atanasov, A. Todorova, Ts. Atanasova, N. Shtrankova, M. Momchilova G. Zsivanovits

\section{Short Communication}

Influence of elevated platform (wire-mesh or wooden) in the cage on domestic rabbit (Oryctolagus cuniculus) activity

S. Peeva, E. Raichev, D. Georgiev, A. Stefanov 


\section{Instruction for authors}

\section{Preparation of papers}

Papers shall be submitted at the editorial office typed on standard typing pages (A4, 30 lines per page, 62 characters per line). The editors recommend up to 15 pages for full research paper ( including abstract references, tables, figures and other appendices)

The manuscript should be structured as follows: Title, Names of authors and affiliation address, Abstract, List of keywords, Introduction, Material and methods, Results, Discussion, Conclusion, Acknowledgements (if any), References, Tables, Figures.

The title needs to be as concise and informative about the nature of research. It should be written with small letter /bold, 14/ without any abbreviations.

Names and affiliation of authors The names of the authors should be presented from the initials of first names followed by the family names. The complete address and name of the institution should be stated next. The affiliation of authors are designated by different signs. For the author who is going to be corresponding by the editorial board and readers, an E-mail address and telephone number should be presented as footnote on the first page. Corresponding author is indicated with *

Abstract should be not more than 350 words. It should be clearly stated what new findings have been made in the course of research. Abbreviations and references to authors are inadmissible in the summary. It should be understandable without having read the paper and should be in one paragraph.

Keywords: Up to maximum of 5 keywords should be selected not repeating the title but giving the essence of study.

The introduction must answer the following questions: What is known and what is new on the studied issue? What necessitated the research problem, described in the paper? What is your hypothesis and goal?

Material and methods: The objects of research, organization of experiments, chemical analyses, statistical and other methods and conditions applied for the experiments should be described in detail. A criterion of sufficient information is to be possible for others to repeat the experiment in order to verify results.

Results are presented in understandable tables and figures, accompanied by the statistical parameters needed for the evaluation. Data from tables and figures should not be repeated in the text. Tables should be as simple and as few as possible. Each table should have its own explanatory title and to be typed on a separate page. They should be outside the main body of the text and an indication should be given where it should be inserted.

Figures should be sharp with good contrast and rendition. Graphic materials should be preferred. Photographs to be appropriate for printing. Illustrations are supplied in colour as an exception after special agreement with the editorial board and possible payment of extra costs. The figures are to be each in a single file and their location should be given within the text.

Discussion: The objective of this section is to indicate the scientific significance of the study. By comparing the results and conclusions of other scientists the contribution of the study for expanding or modifying existing knowledge is pointed out clearly and convincingly to the reader. Conclusion: The most important consequences for the science and practice resulting from the conducted research should be summarized in a few sentences. The conclusions shouldn't be numbered and no new paragraphs be used. Contributions are the core of conclusions. References:

In the text, references should be cited as follows: single author: Sandberg (2002); two authors: Andersson and Georges (2004); more than two authors: Andersson et al.(2003). When several references are cited simultaneously, they should be ranked by chronological order e.g.: (Sandberg, 2002; Andersson et al., 2003; Andersson and Georges, 2004).

References are arranged alphabetically by the name of the first author. If an author is cited more than once, first his individual publications are given ranked by year, then come publications with one co-author, two co-authors, etc. The names of authors, article and journal titles in the Cyrillic or alphabet different from Latin, should be transliterated into Latin and article titles should be translated into English. The original language of articles and books translated into English is indicated in parenthesis after the bibliographic reference $($ Bulgarian $=\mathrm{Bg}$, Russian $=\mathrm{Ru}$, Serbian $=\mathrm{Sr}$, if in the Cyrillic, Mongolian =
Mo, Greek = Gr, Georgian = Geor., Japanese $=\mathrm{Ja}$, Chinese $=\mathrm{Ch}$, Arabic $=\mathrm{Ar}$, etc.)

The following order in the reference list is recommended:

Journal articles: Author(s) surname and initials, year. Title. Full title of the journal, volume, pages. Example:

Simm G, Lewis RM, Grundy B and Dingwall WS, 2002. Responses to selection for lean growth in sheep. Animal Science, 74, 39-50

Books: Author(s) surname and initials, year. Title. Edition, name of publisher, place of publication. Example:

Oldenbroek JK, 1999. Genebanks and the conservation of farm animal genetic resources, Second edition. DLO Institute for Animal Science and Health, Netherlands.

Book chapter or conference proceedings: Author(s) surname and initials, year. Title. In: Title of the book or of the proceedings followed by the editor(s), volume, pages. Name of publisher, place of publication. Example:

Mauff G, Pulverer G, Operkuch W, Hummel K and Hidden C, 1995. C3variants and diverse phenotypes of unconverted and converted C3. In: Provides of the Biological Fluids (ed. $\mathrm{H}$. Peters), vol. 22, 143-165, Pergamon Press. Oxford, UK.

Todorov N and Mitev J, 1995. Effect of level of feeding during dry period, and body condition score on reproductive performance in dairy cows, IX $X^{\text {th }}$ International Conference on Production Diseases in Farm Animals, September 11-14, Berlin, Germany.

Thesis:

Hristova D, 2013. Investigation on genetic diversity in local sheep breeds using DNA markers. Thesis for PhD, Trakia University, Stara Zagora, Bulgaria, (Bg).

The Editorial Board of the Journal is not responsible for incorrect quotes of reference sources and the relevant violations of copyrights.

\section{Animal welfare}

Studies performed on experimental animals should be carried out according to internationally recognized guidelines for animal welfare. That should be clearly described in the respective section "Material and methods". 


\section{AGRICULTURAL \\ SCIENCE AND TECHNOLOGY}

Volume 9, Number 3

September 2017
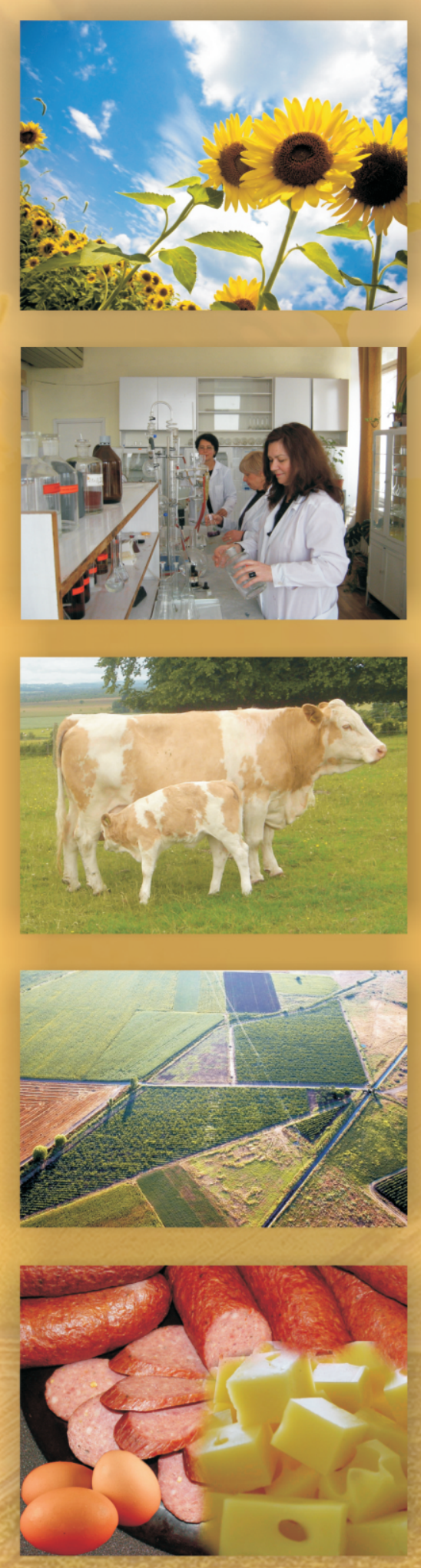

Journal web site: 